\title{
ОСУШУВАЧ ПОВІТРЯ НА БАЗІ ЕЛЕМЕНТА ПЕЛЬТЬЄ ТА АРДУІНО
}

\author{
В. С. Волошин, О. Ю. Азархов, І. І. Сілі \\ ДВНЗ «Приазовський державний технічний університет»
}

\begin{abstract}
Глобальне потепління суттєво впливає та буде надалі впливати на підвищення вологості у світі. I хоча більшість населення України ще не відчула даної проблеми суттєво, є всі передумови вважати, що в близькому майбутньому матимемо щорічне підвищення вологості в усіх містах і селах країни та обмеження доступу населення й установ до питної якісної води. Актуально проблема стане перед містами, що територіально знаходяться біля морського узбережжя, такі як наприклад м. Маріуполь. Звичайно, наявність води для споживання є надзвичайно важливою, оскільки, в свою чергу, це головне джерело життя на Землі. Незважаючи на всю виявлену воду в земній корі, лише 2,5 \% води - прісна вода. 3 цієї найменшої частини 70 \% використовується у сільському господарстві, 23 \% - у галузях промисловості та 7 \% для споживання людиною. У роботі представлено розробку прототипу системи для осушення повітря, що має основну мету - зменшити вологість повітря у приміщенні, в першу чергу закладів охорони здоров'я. Інші переваги включають: акумуляцію технічної води, низьку вартість, маленький розмір, портативність. Для осушувача використовується алюміні-

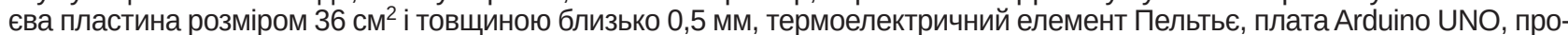
відники-перемички, транзистори TIP122 та резистори опором 1 кОм. У рамках первинних результатів перевірено та отримано процес конденсації водних крапель на алюмінієвій пластині, а сам процес виявився постійним і контрольованим.
\end{abstract}

Ключові слова: вода, вологість, елемент Пельтьє, Ардуіно, осушувач, медичний заклад.

\section{AIR DEHUMIDIFIER BASED ON PELTIER AND ARDUINO}

\author{
V. S. Voloshin, O. Yu. Azarkhov, I. I. Sili \\ Pryazovskyi State Technical University
}

Background. Global warming is having a significant impact and will continue to have an impact on rising global humidity. Although the majority of the Ukraine population has not yet experienced this problem significantly, there are all prerequisites to believe that in the near future we will have an annual increase in humidity in all cities and villages of our country, come with restrict access of the population and facilities to drinking water. The problem will be urgently present to the cities which are territorially located near the sea coast, such as for example Mariupol. Of course, the availability of water for consumption is extremely important because it is the main source of life on Earth. Despite all the water found in the earth's crust, only $2.5 \%$ of the water is fresh water. Of this small part, $70 \%$ is used in agriculture, $23 \%$ in industry and $7 \%$ for human consumption.

Results. This paper presents the development of a prototype of a dehumidification system that has the primary purpose of reducing indoor air humidity, first of all, in health care facilities (by condensation). Other benefits include: technical water storage, low cost, small size, portability. The process of removing water from the air must be clearly monitored so that the relative humidity in the room remains greater than the minimum permissible level. In order to avoid harm to the health of people and patients, humidity should be at least $30 \%$, if less - a possible negative impact on human health could be. The dehumidifier uses a $36 \mathrm{~cm}^{2}$ aluminum plate about $0.5 \mathrm{~mm}$ thick, a Peltier thermoelectric element, an Arduino UNO board, jumper wires, TIP122 transistors and $1 \mathrm{kOhm}$ resistors. The Peltier thermoelectric element is a small unit that uses condensing technology to operate as a heat pump. Its thickness is only a few millimeters, the shape is square, it is $4 \times 40 \times 40 \mathrm{~mm}$, the element contains small cubes of Bi2Te3 (bismuth telluride) in its structure. After connecting and applying voltage (12V) to the Peltier element in 4 minutes, droplets of water began to form on the plate. For ease of maintenance and design, each side of the element was marked with the letters «X» (stands for «cooling side») and «G» (stand for «heating side»). To control the cooler and power supply, the Arduino PWM of the corresponding PIN output was used and a signaling algorithm was installed. Digital control is used to create a square wave, the signal switches between on and off mode.

Conclusions. As part of the initial results, we tested and obtained the process of condensation of water droplets on an aluminum plate, and the process itself turned out to be continuous and controlled. An important element in the further development of a generic model of dehumidifier for use in healthcare facilities should be the implementation of system feedback, such as the use of an Arduino-enabled humidity sensor.

Key words: water, humidity, Peltier element, Arduino, dehumidifier, medical facility 


\title{
ОСУШИТЕЛЬ ВОЗДУХА НА БАЗЕ ЭЛЕМЕНТА ПЕЛЬТЬЕ И АРДУИНО \\ В. С. Волошин, А. Ю. Азархов, И. И. Сили ГВУЗ «Приазовский Государственный Технический Университет»
}

\begin{abstract}
Глобальное потепление существенно влияет и будет в дальнейшем влиять на повышение влажности в мире. И хотя большинство населения Украины еще не почувствовали данной проблемы существенно, есть все предпосылки считать, что в ближайшем будущем мы получим ежегодное повышение влажности во всех городах и селах нашего государства наряду с ограничением доступа населения и учреждений к питьевой качественной воде. Актуально проблема предстанет перед городами, которые территориально находятся у морского побережья, такие как например г. Мариуполь. Конечно, наличие воды для потребления является чрезвычайно важным, поскольку, в свою очередь, это главный источник жизни на Земле. Несмотря на всю имеющуюся воду в земной коре, лишь 2,5 \% воды - пресная вода. Из этой маленькой части 70 \% используется в сельском хозяйстве, $23 \%$ - в отраслях промышленности и 7 \% - для потребления человеком. В работе представлена разработка прототипа системы для осушения воздуха, которая имеет основную цель - уменьшить влажность воздуха в помещении, в первую очередь учреждений здравоохранения (при помощи конденсации). Другие преимущества включают: аккумуляция технической воды, низкая стоимость, небольшой размер, портативность. Для осушителя используется алюминиевая пластина размером 36 см $^{2}$ и толщиной около 0,5 мм, термоэлектрический элемент Пельтье, плата Arduino UNO, проводники-перемычки, транзисторы TIP122 и резисторы сопротивлением 1 кОм. В рамках первичных результатов проверено и получено процесс конденсации водных капель на алюминиевой пластине, а сам процесс оказался постоянным и контролируемым.
\end{abstract}

Ключевые слова: вода, влажность, элемент Пельтье, Ардуино, осушитель, медицинское учреждение. 
Вступ. Глобальне потепління суттєво впливає та буде надалі впливати на підвищення вологості у світі. I хоча більшість населення України ще не відчула даної проблеми суттєво, $\epsilon$ всі передумови вважати, що в близькому майбутньому матимемо щорічне підвищення вологості в усіх містах і селах країни разом із обмеженням доступу населення й установ до питної якісної води. Актуально проблема стане перед містами, що територіально знаходяться біля морського узбережжя, такі як наприклад м. Маріуполь. Звичайно, наявність води для споживання є надзвичайно важливою, оскільки, в свою чергу, це головне джерело життя на Землі. Важливість води для виживання життя на землі беззаперечна, оскільки ії використовують для виробництва продуктів харчування, вироблення енергії, споживання людиною, тваринництва та інше.

За даними [1] при загальній кількості води в усьому світі у 100 \%, приблизно 97,5 \% не підходить для споживання людиною, ця вода солона, і лише решта - 2,5 \%, прісні води. Однак із цього невеликого відсотка, менше третини (1,2 \% на поверхні землі та 30,1 \% у грунті) складає питна вода. Повний розподіл представлено на рис. 1.
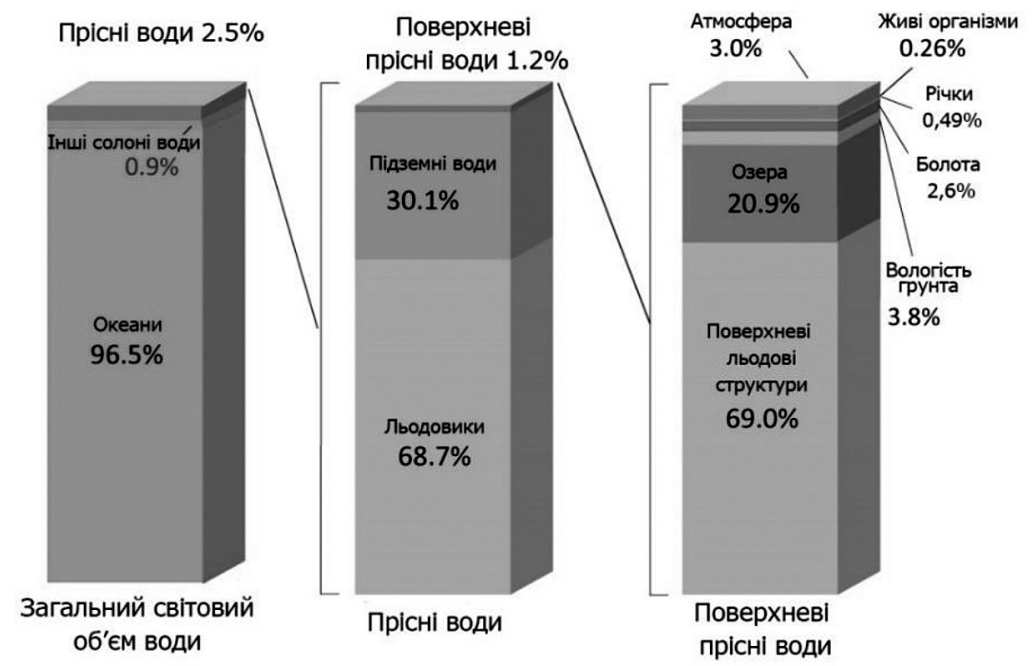

Рис. 1. Розподіл світових водних запасів

За іншими даними [2], вважається, що серед $100 \%$ прісної питної води в усьому світі 70 \% використовується в сільському господарстві (шляхом зрошення), 23 \% використовуються в промисловості та лише 7 \% споживає людина (рис. 2).

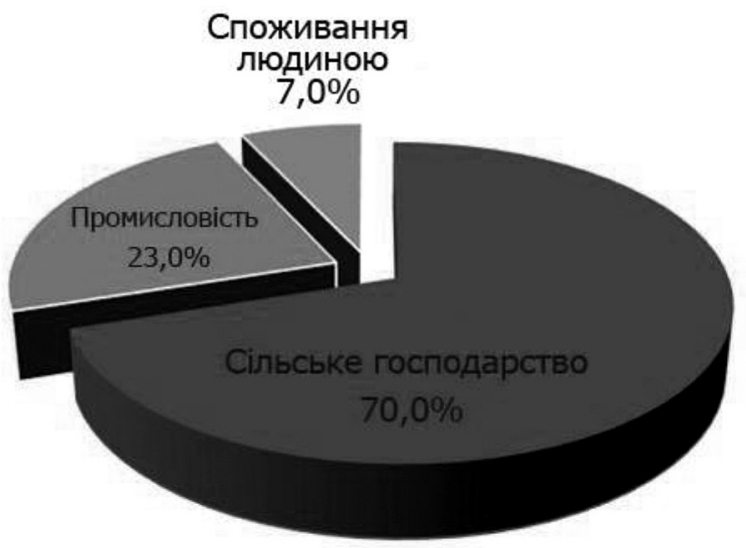

Рис. 2. Споживання води у світі

Через обмежену кількість води по відношенню до загального відсотка населення та великі відходи очищеної води, пропонується конструкція осушувача повітря, що конденсуватиме воду з повітря за допомогою термоелектричних елементів Пельтьє, процес конденсування контролюватиметься платформою Ардуіно за окремою програмою. Тобто, можна, по-перше, зменшити вологість повітря у приміщені до необхідного санітарного рівня, наприклад, у медичних закладах, а по-друге, 
акумулювати воду в спеціальних ємностях із подальшим використанням у технічних цілях.

Мета роботи: представити розробку прототипу системи для осушення повітря, що має основну мету — зменшення вологості повітря у приміщенні, в першу чергу, закладів охорони здоров’я (за допомогою конденсації).

Матеріал і методи дослідження. Процес видалення води з повітря має чітко контролюватися, щоб відносна вологість у медичному приміщенні залишилась більшою за мінімально допустимий рівень. Щоб уникнути шкоди здоров’ю пацієнтів і персоналу, вологість повинна становити принаймні 30 \%, якщо менше - можливий негативний вплив на здоров’я людини [3]. Конденсація води може здійснюватися в атмосферному повітрі на охолоджуючій поверхні, температура якої нижче точки роси, де конденсується волога. Тому для отримання води на конденсаційному осушувачі необхідно і достатньо, щоб поверхня осушувача була нижчою, ніж температура навколишнього середовища.
Термоелектричний елемент Пельтьє - це невеликий блок, що використовує технологію конденсації для роботи в якості теплового насоса. Його товщина складає всього кілька міліметрів, форма - квадратна, вона становить 4×40×40 мм, елемент містить невеликі кубики Вi2Te3 (теллурид вісмуту) у своїй будові [4]. На рис. 3 показано термоелектричний елемент Пельтьє ТЕС1-12706, що використано при розробці моделі.

Ефект Пельтьє був відкритий у 1834 р. Модулі на базі Пельтьє ефекту зазвичай складаються 3 пропорційних напівпровідникових матеріалів, що створюють напівпровідники Р-типу та $\mathrm{N}$-типу. При подачі електричного струму, одні матеріали отримують електрони, інші віддають, у результаті чого одна сторона елемента нагрівається, а протилежна охолоджується [4]. Для простоти обслуговування та при конструюванні кожна сторона елемента була відмічена літерами «Х» (охолоджуюча сторона) та «Г» (нагріваюча сторона).

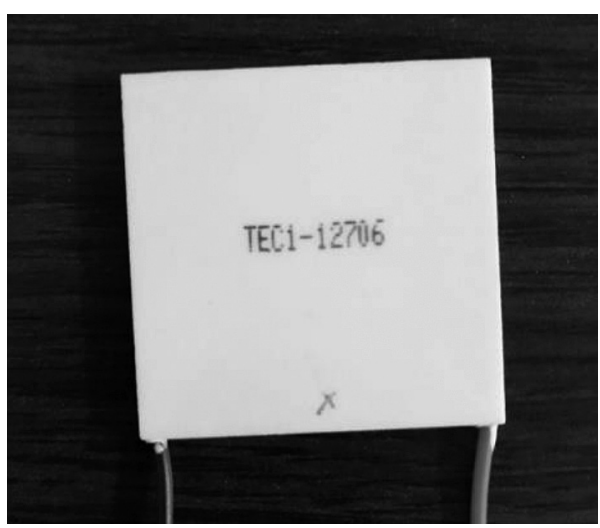

Рис. 3. Термоелектричний елемент Пельтьє ТЕС1-12706

Використання термоелектричного модуля Пельтьє, в якості осушувача дозволяє знизити вартість обладнання, досягти невеликих компактних розмірів і знизити ризик ураження електричним струмом при використанні некваліфікованим персоналом. Також важливими фактором є здатність осушувача на елементі Пельтьє ефективно підтримувати низьку температуру однієї із сторін, порівняно з температурою навколишнього середовища.

Транзистор типу TIP122 дозволяє при отриманні дуже слабкого сигналу на вході (базі), перетворювати його на потужний сигнал на виході (колектор або емітер) транзистора.

Резистори - це компоненти, що можна використовувати як регулятор, задати або обмежити значення протікаючого струму. Їх підбирають за кольором, що знайдено на їх поверхні, для нашого прототипу був використаний резистор 1 КОм.

Для контролю процесу конденсації було обрано платформу Arduino, оскільки ця технологія прототипування - 3 відкритим кодом, та заснована на апаратному та програмному забезпеченні. У Arduino використовується мікроконтролер ATMEL AVR з підтримкою сигналів на вході та виході. Як відомо, Arduino використовує стандартне програмування $\mathrm{C} / \mathrm{C}++$ [5]. Алгоритм управління будемо проводити за допомогою програмного забезпечення Arduino IDE.

Для управління охолоджувачем та джерелом живлення було використано ШІМ Arduino відповідного PIN виходу та встановлено алгоритм подачі сигналів. Цифрове керування використовується для 
створення квадратної хвилі, сигнал перемикається між увімкненим та вимкненим режимом.

Результати та їх обговорення. Для осушувача було обрано алюмінієву пластину приблизно 36 см², товщиною близько 0,5 мм, три термоелектричні елемента Пельтьє TEC1-12706, радіатор, Arduino Uno, плата для з’єднань, перемички, зовнішній блок живлення 220/12B, три транзистори ТIP 122 , три резистори 1 кОм, цифровий термометр та мультіметр як показано на рис. 4. Елемент Пельтьє монтувався на зворотній стороні пластини холодною стороною до алюмінієвої пластини, цифровим термометром контролювалась температура холодної сторони. Під час проведення досліду стало зрозуміло, що з нагріваючої сторони елемента необхідно додатково встановити радіатор для охолодження та уникнення перегріву і виходу з ладу модуля Пельтьє.

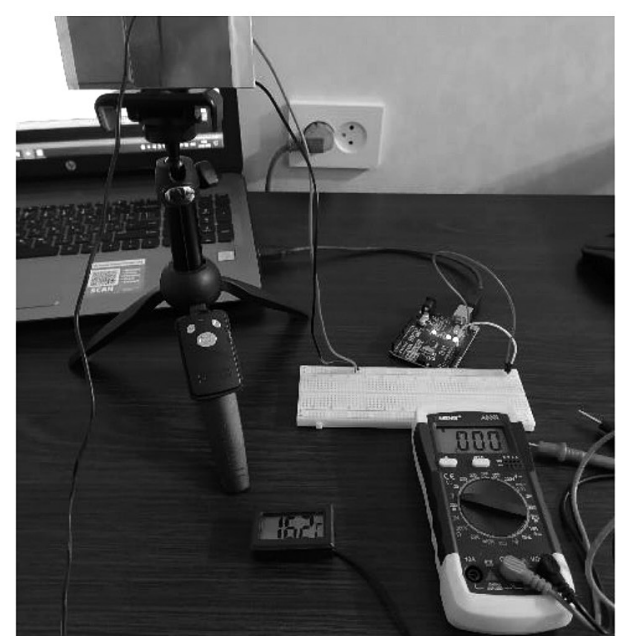

а) дослідна модель

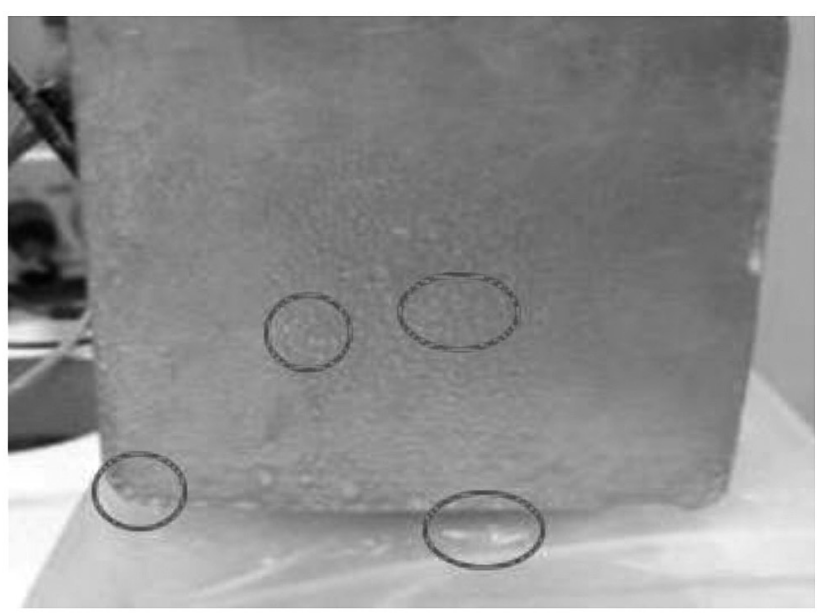

б) конденсація крапель води

Рис. 4. Проведення досліду з осушувачем повітря на базі модуля Пельтьє

За допомогою мультиметра встановлювалась вихідна напруга зовнішнього джерела живлення у межах 12 В \pm 1 В та контролювалась сила струму протікаючого через модуль Пельтьє. Час та тривалість подачі струму здійснювалась за допомогою плати Arduino та розробленого алгоритму.

Програма алгоритму роботи осушувача на Ардуіно, при проведені досліду має такий вид:

int peltier $=3$;

int power $=0$;

int peltier_level = map(power, 0, 99, 0, 255);

void setup( $)\{$

Serial.begin(9600);

//pinMode(peltier, OUTPUT);

\}

void $\operatorname{loop}()\{$

char option;

if(Serial.available ()$>0)$

\{

option = Serial.read();

if(option $==$ ' $a$ ')

power $+=5$;

else if(option $==$ ' $\mathrm{z}$ ')

power $-=5$;

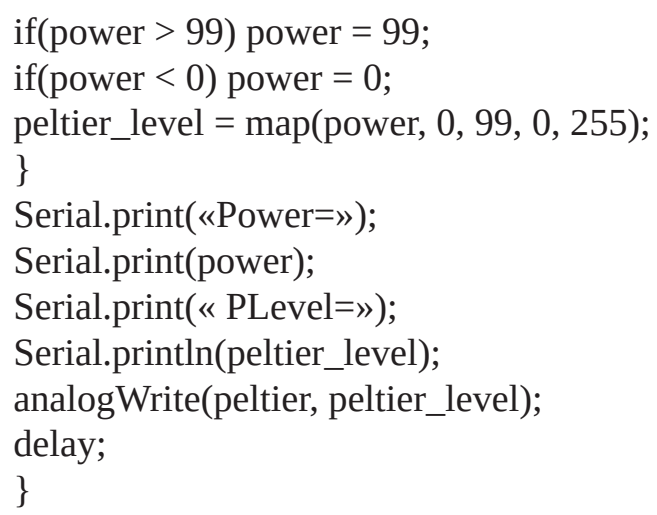

Після підключення та подачі напруги (12 В) на елемент Пельтьє було заміряно мінімально низьку температуру алюмінієвої пластини $\mathrm{t}=-2^{\circ} \mathrm{C}$, при цьому температура навколишнього середовища tн.c $=18^{\circ} \mathrm{C}$. Через приблизно 4 хвилини на пластині почали формуватися крапельки води.

Висновки. На основі проведеного дослідження, можна стверджувати, що осушувач повітря досить ефективний пристрій, який конденсуючи краплі води з пари у повітрі з більшою концентрацією мікро крапель на алюмінієвій пластин, поперше, зменшує вологість повітря у приміщенні, 
а по-друге є джерелом технічної води в невеликих кількостях. Об’єм конденсованої води буде залежати від початкової вологості приміщення та часу роботи пристрою. Видалена вода з повітря може зберігатися в будь-якому контейнері, наприклад у вигляді ПЕТ-пляшки або кварцової трубки. За нашими розрахунками при об’ємі осушуючого приміщення в 1 м $^{3}$ даний прототип здатен зменшити вологість повітря на 1 \% за 15 хвилин.

Однак, дані дослідження лише використовують прототип 3 обмеженими розмірами пластини

\section{Література.}

1. NASA-Water: The World's Water: Distribution of Earth's Water. URL: https://water.usgs.gov/edu/ earthwherewater.html. — Accessed 22 Apr. 2020.

2. Operational water consumption and withdrawal factors for electricity generating technologies: a review of existing literature / Macknick J., Newmark R., Heath G., Hallett K. C. // Cambridge, Harvard Kennedy School. — 2012. — Vol. 7 (4). - P. 52.

3. ДСН 3.3.6.042-99. Санітарні норми мікроклімату виробничих приміщень. Постанова КМУ № 42 від 01.12.1999. — м. Київ. — 1999.

4. Physics of Transition Metal Oxides / Sadamichi M., Takami T., Stewart E. B. et al. — Springer-Verlag, Berlin Heidelberg, 2004. — https://doi.org/10.1007/978-3662-09298-9.

5. Arduino: What is Arduino. - Режим доступу: https:// www.arduino.cc/en/Guide/Introduction (accessed 20 Apr 2020).

6. Основи теорії керування в біомедичних системах [Електронний ресурс] : конспект лекц. 3 дисцип. «Основи теорії керування в біомедичних системах» для студ. спец. 163 «Біомедична інженерія» освітньої програми «Біомедична інженерія» денної форми навчання / уклад.: І. І. Сілі, Н. А. Бухлал. - Маріуполь : ПДТУ, 2020. - 117 с. алюмінію та елементів Пельтьє, вважаємо доцільним розширювати розміри прототипу у майбутніх проєктах у напряму його більш ефективного виробництва води через конденсацію. Важливим елементом в подальшому, при створенні загальної моделі осушувача для використання у медичних закладах, має бути реалізація зворотного зв’язку системи [6], наприклад використання датчику вологістю з підтримкою Arduino. Система буде повністю автоматичною з підтримкою заданого параметру вологості.

\section{References.}

1. NASA-Water: The World's Water: Distribution of Earth's Water. (2020). Retrieved from: https://water.usgs.gov/ edu/earthwherewater.html (accessed 22 Apr. 2020).

2. Macknick, J., Newmark, R., Heath, G., Hallett, K. C. (2012). Operational water consumption and withdrawal factors for electricity generating technologies: a review of existing literature. Harvard Kennedy School, Environmental Research Letter, 7(4), 52.

3. DSN 3.3.6.042-99 (1999). Sanitarni normi mikroklimatu virobnichih primishen. Санітарні норми мікроклімату виробничих приміщень [Sanitary standards for microclimate]. Resolution of the Cabinet of Ministers of Ukraine № 42 of 01.12.99. [In Ukrainian].

4. Sadamichi, M., Takami, T., Stewart, E. B., Sumio, I., Wataru, K., Giniyat, Kh. (2004). Physics of Transition Metal. Oxides Springer-Verlag, print ISBN 978-3-64205963-6. Berlin Heidelberg. Retrieved from: https://doi. org/10.1007/978-3-662-09298-9.

5. Arduino: What is Arduino. (2020). Retrieved from: https:// www.arduino.cc/en/Guide/Introduction.

6. Sili, I. I., Buhlal, N. A. (2020). Osnovi teoriyi keruvannya $\mathrm{v}$ biomedichnih sistemah [Fundamentals of control theory in biomedical systems]. Konspekt lekcij z disciplini «Osnovi teoriyi keruvannya v biomedichnih sistemah» dlya studentiv specialnosti 163 «Biomedichna inzheneriya» osvitnoyi programi «Biomedichna inzheneriya» dennoyi formi navchannya (lecture notes on the discipline «Fundamentals of control theory in biomedical systems» for students majoring in 163 «Biomedical Engineering» educational program «Biomedical Engineering» full-time education), Mariupol : PDTU, 117. Retrieved from: http://umm. pstu.edu/handle/123456789/19988. 